\title{
Hydrodynamics of submersible aquaculture cage system using numerical model
}

\author{
Tae-Ho KIM*, David W. FredriKsson ${ }^{1}$ and Judson DeCeW ${ }^{2}$ \\ Faculty of Marine Technology, Chonnam National University, Jeonnam 550-749, Korea \\ ${ }^{1}$ Department of Naval Architecture and Ocean Engineering, United States Naval Academy, \\ Annapolis, MD 21402, USA \\ ${ }^{2}$ Department of Mechanical Engineering, University of New Hampshire, \\ Durham, NH 03824, USA
}

\begin{abstract}
A numerical model analysis was performed to analyze the motion and mooring tension response of submersible fish cage systems in irregular waves and currents. Two systems were examined: a submersible cage mooring with a single, high tension mooring and the same system, but with an additional three point mooring. Using a Morison equation type model, simulations of the systems were conducted with the cage at the surface and submerged. Irregular waves(JONSWAP spectrum) with and without a co-linear current with a magnitude of $0.5 \mathrm{~m} / \mathrm{s}$ were simulated into the model as input parameters. Surge, heave and pitch dynamic calculations were made, along with tension responses in the mooring lines. Results were analyzed in both the time and frequency domains and linear transfer functions were calculated.
\end{abstract}

Key words : Motion, Mooring tension, Submersible cage system, Irregular waves

\section{Introduction}

In this study, a numerical modeling was conducted to investigate the hydrodynamics of submersible aquaculture cage system, consisting of a modified gravity cage in irregular waves and current. It builds on a past study(Kim, 2006) that included mooring loads analysis of the submersible aquaculture cage system in regular waves and currents using finite element method. In both cases, the system is analyzed using two mooring configurations. The first consists of a single point, high tension mooring that passes through the cage, while the second mooring configuration consists of the same single point component with three additional anchor legs connected to the upper rim. The numerical model uses the finite element analysis approach described by Tsukrov et al. (2003, 2005). The results of past model simulations have compared well with both physical model tests and field measurements for a variety of cage/ mooring configurations and conditions(DeCew et al., 2005; Fredriksson et al., 2003a, 2003b, 2003c,

*Corresponding author: kimth@chonnam.ac.kr, Tel: 82-61-659-3121, Fax: 82-61-659-3121 
2005). A summary of many of the numerical modeling case studies can be found in Fredriksson et al. (2003d). Though the results of the model should only be considered approximate, insight can be gained regarding the tension in mooring components and the motion response of the fish containment structure.

The objective of this study is to determine the cage motion and mooring tension characteristics of a specific submersible aquaculture cage with two different mooring designs in response to extreme irregular waves with and without a co-linear superimposed current. A numerical model was constructed, simulations were performed and spectral response results obtained.

\section{Materials and methods}

The submersible aquaculture system that was analyzed consisted of a modified gravity cage with three primary structural components. The components consist of a monitoring float, an upper frame and a lower frame. The general cage dimensions are provided in Kim(2006). The volume of the cage is maintained by having flotation at the top and weight on the bottom of the structure. The total volume of the system is modeled at approximately $1,800 \mathrm{~m}^{3}$. The general configuration of the cage with the primary structural components is shown in Fig. 1. In this analysis, the system model incorporates the cage with two mooring configurations. The first configuration consists of a single, hightension mooring line that passes from the surface through the cage and is moored at the bottom. The second configuration is the same as the first except three additional anchor legs are attached to the upper frame. In each configuration, the cage can be submerged through an arrangement of pulley systems. Detailed schematics of the two mooring

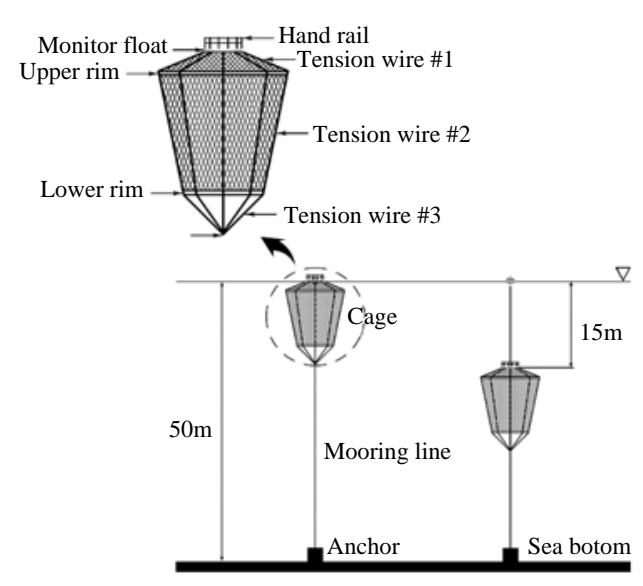

Fig. 1. Construction details of the submersible aquaculture cage system. The system was at the surface(left) and submerged(right) in a single point mooring.

configurations are also provided in Kim(2006).

The three point mooring incorporated bridle lines connected to compensator floats. The system is designed so that the floats would sit at the surface with the cage, and be pulled underneath the water when the cage was submerged. Mooring lines connect the compensator floats to the seafloor. The centralized high tension mooring component(used in the single point system) remained to facilitate submerging the cage. The nodes at the base of both the single point and three mooring leg systems were modeled as fixed points.

Due to the octagonal shape of the cage, the bridle lines were distributed around the rim. This orientation allowed the line absorbing the tension to distribute the load to the rim. The mooring line length was set to have a 4:1 scope, with a length of $200 \mathrm{~m}$ in water $50 \mathrm{~m}$ deep. The compensator floats are placed at the point where the bridle lines are connected to the anchor legs. The bridle lines are connected to the upper rim to the compensator floats, joining the mooring line approximately $25 \mathrm{~m}$ from the center of the cage rim. 
The mooring lines are made of high strength polyethylene rope(Dyneema). The containment net of the cage is made of square type Nylon netting (Td $210 \times 60)$ with mesh size of $60.6 \mathrm{~mm}$.

\section{Numerical model}

\section{Background}

Numerical model simulations were performed using a finite element computer program developed specifically for marine aquaculture applications, Aqua-FE. The program is described in Tsukrov et al. (2003, 2005). Wave and current loadings on truss and buoy elements were introduced by utilizing the Morison equation(Morison et al., 1950). The algorithm employs a nonlinear Lagrangian formulation to account for large displacements of structural elements. In addition, the unconditionally stable Newmark direct integration scheme was adopted to solve the nonlinear equations of motion. Hydrodynamic forces on the structural elements are calculated using the Morison equation modified to account for relative motion between the structural element and the surrounding fluid as described by Haritos and $\mathrm{He}(1992)$.

High level of care must be exercised when modeling the nets of the aquaculture cage. The numerical modeling approach uses a net element that is constructed to reproduce the drag, buoyancy, inertial and elastic forces that are exerted on the structure by waves and currents. A modeling technique was developed, called the "Consistent Net Element", that considers these important forces, since direct finite element modeling of all the strands is impractical. The detailed approach is described explicitly in Tsukrov et al.(2003).

\section{Input parameters}

The numerical model was used for a total of 12 simulations. Static simulations were first performed to verify system stability. A simulation was performed for each of the mooring configurations with the cage at the surface and submerged. Forced environmental input consisted of an irregular wave profile with and without a superimposed co-linear current with a magnitude of $0.5 \mathrm{~m} / \mathrm{s}$. To obtain an irregular wave profile in the numerical routine, a spectrum is decomposed into multiple frequency components. The spectrum chosen was a form of the Joint North Sea Wave Project(JONSWAP) spectrum(Hasselman et al., 1973; Goda, 2000) described as

$$
S(f)=\alpha H_{S}^{2} T_{p}^{-4} f^{-5} \exp \left[-1.25\left(T_{p} f\right)^{-4}\right] \gamma^{Y}
$$

where

$$
\begin{aligned}
Y & =e^{\left[-\left(T_{p} f-1\right)^{2} / 2 \sigma^{2}\right]} \\
\alpha & =\frac{0.0624}{0.23+0.0336 \gamma-0.185(1.9+\gamma)^{-1}} \\
\sigma & =\left\{\begin{array}{l}
\sigma_{a}=f \leq f_{p} \\
\sigma_{b}=f \geq f_{p}
\end{array}\right.
\end{aligned}
$$$$
\text { and }
$$

and $f_{p}$ is the frequency at the spectral peak $\left(1 / T_{p}\right)$. Parameters $\gamma$ and $\sigma$ are used to adjust the height and width of the peak of the curve, respectively. In this study, the default shaping parameters used are provided in Table 1, along with an $H_{s}$ of $8.64 \mathrm{~m}$ and a $T_{p}$ of $12.73 \mathrm{sec}$, which were chosen according to the design waves data of the coastal areas in the southern sea of Korea during the past 20 years(see http://www.kordi.re.kr). The current of $0.5 \mathrm{~m} / \mathrm{s}$ is

Table 1. The JONSWAP parameters used to shape the input spectrum

\begin{tabular}{cc}
\hline Parameter & Value \\
\hline $\mathrm{H}_{\mathrm{s}}(\mathrm{m})$ & 8.64 \\
$\mathrm{~T}_{\mathrm{p}}(\mathrm{sec})$ & 12.73 \\
$\gamma$ & 3.3 \\
Power off & -5 \\
$\sigma_{a}$ & 0.2049 \\
$\sigma_{b}$ & 0.0785 \\
\hline
\end{tabular}


consistent with depth and water at of 50m depth.

In addition to the wave input parameters, the numerical model requires all of the geometric and material properties of the fish cage and mooring system. The parameters include the mass density, Young's modulus and cross sectional area of each element component. The cage and mooring component material and geometric properties used in the numerical model simulations are provided in $\operatorname{Kim}(2006)$.

\section{Cage motion response locations}

For each simulation, motion response datasets were acquired to characterize the motion of the cage. The node locations for the monitoring float, and upper and lower rims chosen are shown in Fig. 2.

In the first set of dynamic simulations, the submersible fish cage was analyzed using the single point mooring. In this configuration, the cage was modeled at the surface and submerged. Simulations were performed using irregular waves with and without the co-linear current of $0.5 \mathrm{~m} / \mathrm{s}$. The numerical model representation of this system is also shown in Kim(2006), which includes the locations of the elements. The submersible aquaculture fish cage motion response(surge, heave

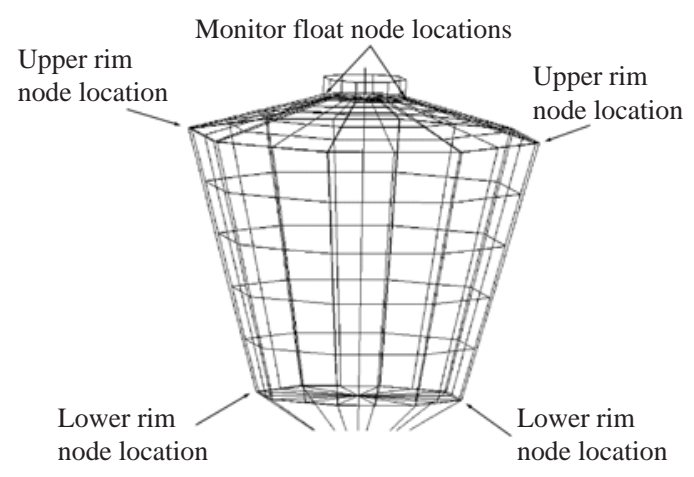

Fig. 2. Schematic of the node locations where the motion data was analyze. and pitch) was examined. The cage motion response locations analyzed were consistent for each of the load cases. In addition to the motion response results, mooring line tension was obtained from the stress calculated in each of the elements.

The same motion response datasets were obtained for the cage using the single point mooring in the submerged configuration. In addition to the motion response datasets, two mooring line tensions from two locations were calculated using the numerical model. The tension values from above and below the cage were acquired. Similar numerical model simulations were performed using the single point mooring with three anchor legs. Motion response datasets were also generated for the same cage locations as previously described. For the three point mooring in the submerged configuration, the same motion response datasets were obtained.

\section{Data analysis}

Numerical model simulations were conducted using irregular waves. Irregular waves(and the system response) can be described by a spectrum in the frequency domain in terms of units proportional to energy per frequency band. The wave elevation auto-spectrum is typically described by the significant wave height and the dominant wave period. In a statistical sense, the significant wave height is often estimated from the $H_{m o}$ and is calculated from the zeroth moment of the spectrum,

$$
m_{j}=\int_{0}^{\infty} f^{j} G(f) d f \text {, where } j=0 \cdots n
$$

in the case where $j=0$ and $G(f)$ is the one sided wave elevation auto-spectral density. The zeroth moment of the spectrum is also the area under the spectral curve equal to the variance. If the spectrum is narrow banded and the wave heights follow a 
Rayleigh probability distribution(Ochi, 1998), the $H_{m o}$ is obtained from,

$$
H_{m o}=4 \sqrt{m}_{o}
$$

In deep water, the $H_{m o}$ is approximately equal to the average of the top third wave height (Shore Protection Manual, 1984), which is the significant wave height $\left(H_{s}\right)$ used in the JONSWAP spectrum. The dominant wave period, $T_{p}$, is one over the frequency where the maximum energy in a spectrum occurs.

The wave elevation auto-spectrum is calculated from the measured times series using a discrete form of

$$
S_{x x}(f)=\lim _{T \rightarrow \infty} \frac{1}{2 T} X(f) X^{*}(f)
$$

where $S_{x x}(f)$ is the two sided, auto-spectral density function, $X^{*}(f)$ is the complex conjugate of $X(f)$ and $T$ is the record length. The two sided auto-spectral density function is continuous for all frequencies between $-\infty$ and $\infty$. In standard observational practice, however, the one sided auto-spectral density function, $G_{x x}(f)$, is used, where,

$$
G_{x x}(f)=2 S_{x x}(f) \quad 0 \leq f \leq \infty
$$

Note that $G_{x x}(f)$ could be the same term used in equation (2). For the irregular wave simulations, linear transfer functions were calculated as a function of frequency using auto- and cross-spectral methods. In the frequency domain, the system forcing can be described in terms of energy density as the $G_{\zeta \zeta}(f)$ that is wave excursion auto-spectrum $\left(\mathrm{m}^{2} / \mathrm{Hz}\right), G_{\eta \eta}(f)$ that is wave elevation auto-spectrum $\left(\mathrm{m}^{2} / \mathrm{Hz}\right)$, and $G_{\theta \theta}(f)$ that is wave slope auto- spectrum $\left(\mathrm{rad}^{2} / \mathrm{Hz}\right)$.

The wave excursion and slope auto-spectra are calculated from the wave elevation auto-spectrum using the following relationships,

$$
G_{\zeta \zeta}(f)=G_{\eta \eta}(f) \cdot[\tanh (k d)]^{-2}
$$

and

$$
G_{\theta \theta}(f)=G_{\eta \eta}(f) \cdot(k)^{2}
$$

respectively, where $k=k(f)$ according to the dispersion relation.

Likewise, the auto-spectral motion response in surge, heave, pitch and tension response in the mooring line are calculated using $G_{s s}(f)$ that is surge response auto-spectrum $\left(\mathrm{m}^{2} / \mathrm{Hz}\right), G_{h h}(f)$ that is heave response auto-spectrum( $\left(\mathrm{m}^{2} / \mathrm{Hz}\right), G_{p p}(f)$ that is pitch response auto-spectrum( $\left(\mathrm{rad}^{2} / \mathrm{Hz}\right)$ and $G_{t t}(f)$ that is mooring element tension response autospectrum $\left(\mathrm{kN}^{2} / \mathrm{Hz}\right)$.

To obtain the linear transfer function using the auto-spectral technique between the forcing and the response, the following calculations are made:

$$
\begin{aligned}
& \left|H_{s s}(f)\right|=\left[\frac{G_{s s}(f)}{G_{\zeta \zeta}(f)}\right]^{\frac{1}{2}} \\
& \left|H_{h h}(f)\right|=\left[\frac{G_{h h}(f)}{G_{\eta \eta}(f)}\right]^{\frac{1}{2}} \\
& \left|H_{p p}(f)\right|=\left[\frac{G_{p p}(f)}{G_{\theta \theta}(f)}\right]^{\frac{1}{2}} \\
& \left|H_{t t}(f)\right|=\left[\frac{G_{t t}(f)}{G_{\eta \eta}(f)}\right]^{\frac{1}{2}}
\end{aligned}
$$

where $H_{s s}(f)$ is surge transfer function, $H_{h h}(f)$ is heave transfer function, $H_{p p}(f)$ is pitch transfer function and $H_{t t}(f)$ is mooring element tension transfer function.

\section{Results and discussion}

\section{Hydrostatic analysis}

The first set of numerical model simulations were performed without wave and current loadings. In each of the simulations, the buoyancy of the 
cage created vertical motion as the mooring lines stretched, pre-tensioning the components. The static simulation results for each mooring element are provided in Table 2 . The static tension in the single(vertical) mooring element is primarily due to the buoyancy of the cage and the monitoring floats. The static tensions in the three point mooring components are due to the buoyancy of the compensator floats.

\section{Dynamic analysis}

Once the static simulations were complete, irregular wave simulations were performed with and without the $0.5 \mathrm{~m} / \mathrm{s}$ co-linear current. The time series generated by the numerical model was processed to obtain the wave elevation autospectrum. The dominant wave periods were slightly less than the input values because of the wave frequency resolution used to generate the time series.

Dynamic simulations were also performed for the entire submersible fish cage and mooring system using the environmental parameters and geometric and material properties previously

Table 2. Static tensions in the mooring element calculated using the model

\begin{tabular}{lccccc}
\hline \multirow{2}{*}{ Configuration } & \multicolumn{3}{c}{ Static tension(kN) } & \\
\cline { 2 - 5 } & $\# 1$ & $\# 2$ & $\# 3$ & - & - \\
\hline Single point mooring: Surface & 25.45 & - & - & - & - \\
Single point mooring: Submerged & 23.50 & 5.28 & - & 1.06 & - \\
Three point mooring: Surface & 25.80 & 0.82 & 1.06 & 1.71 \\
Three point mooring: Submerged & 26.52 & 5.28 & 1.52 & 1.71 \\
\hline
\end{tabular}

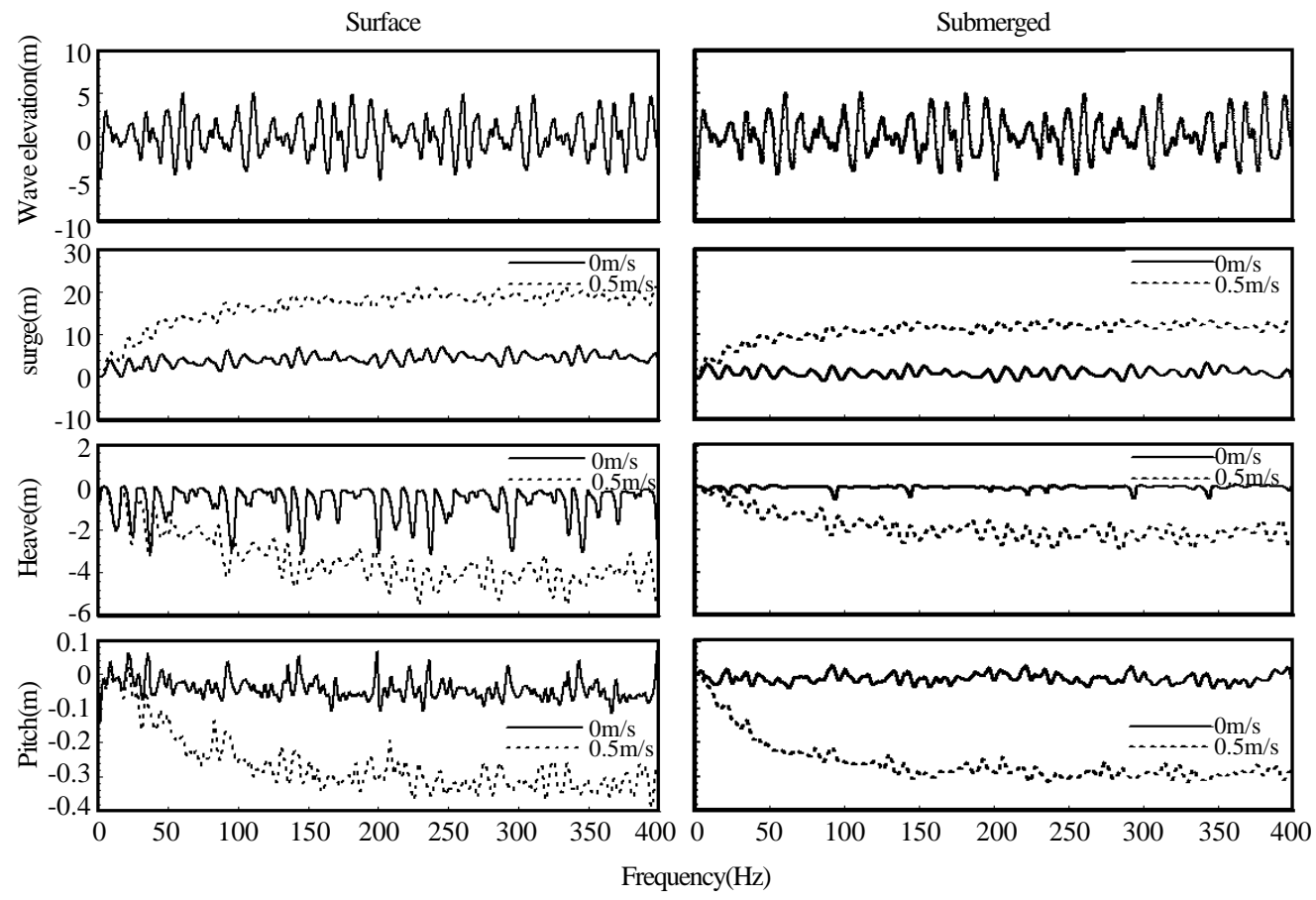

Fig. 3. The motion response time series of submersible fish cage at the surface and submerged for random wave conditions with 0 and $0.5 \mathrm{~m} / \mathrm{s}$ in a single point mooring. 


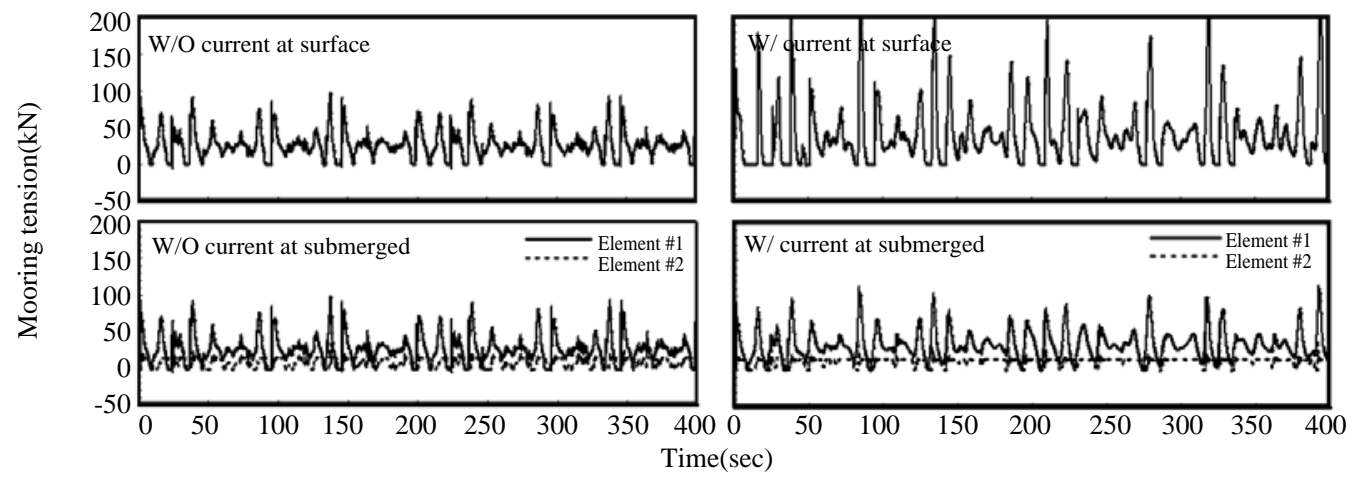

Fig. 4. The mooring tension response for the random wave conditions at 0 and $0.5 \mathrm{~m} / \mathrm{s}$. The system was at the surface and submerged in a single point mooring.
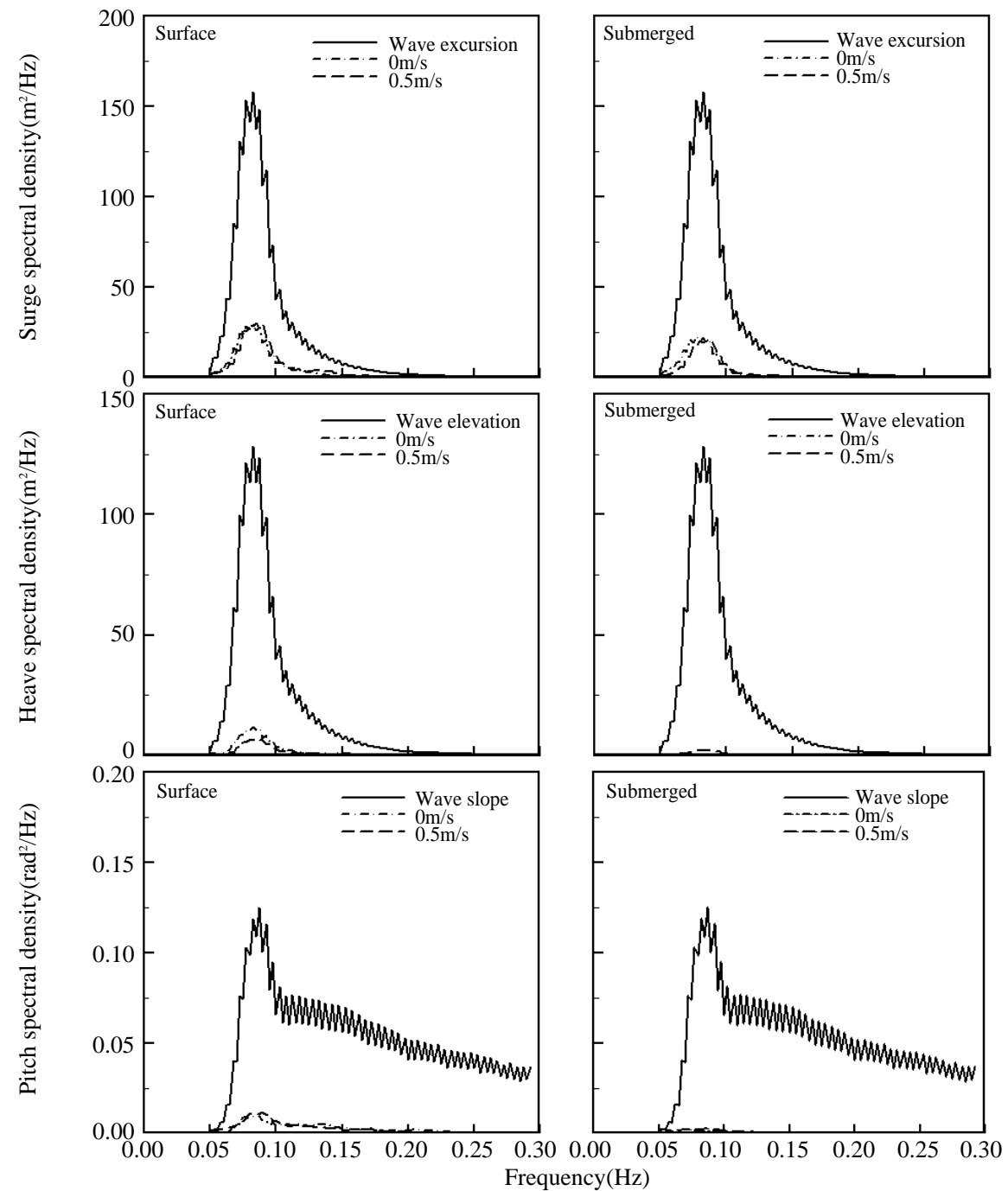

Fig. 5. The wave spectrum parameter input and the motion spectral results at 0 and $0.5 \mathrm{~m} / \mathrm{s}$. The system was at the surface and submerged in a single point mooring. 


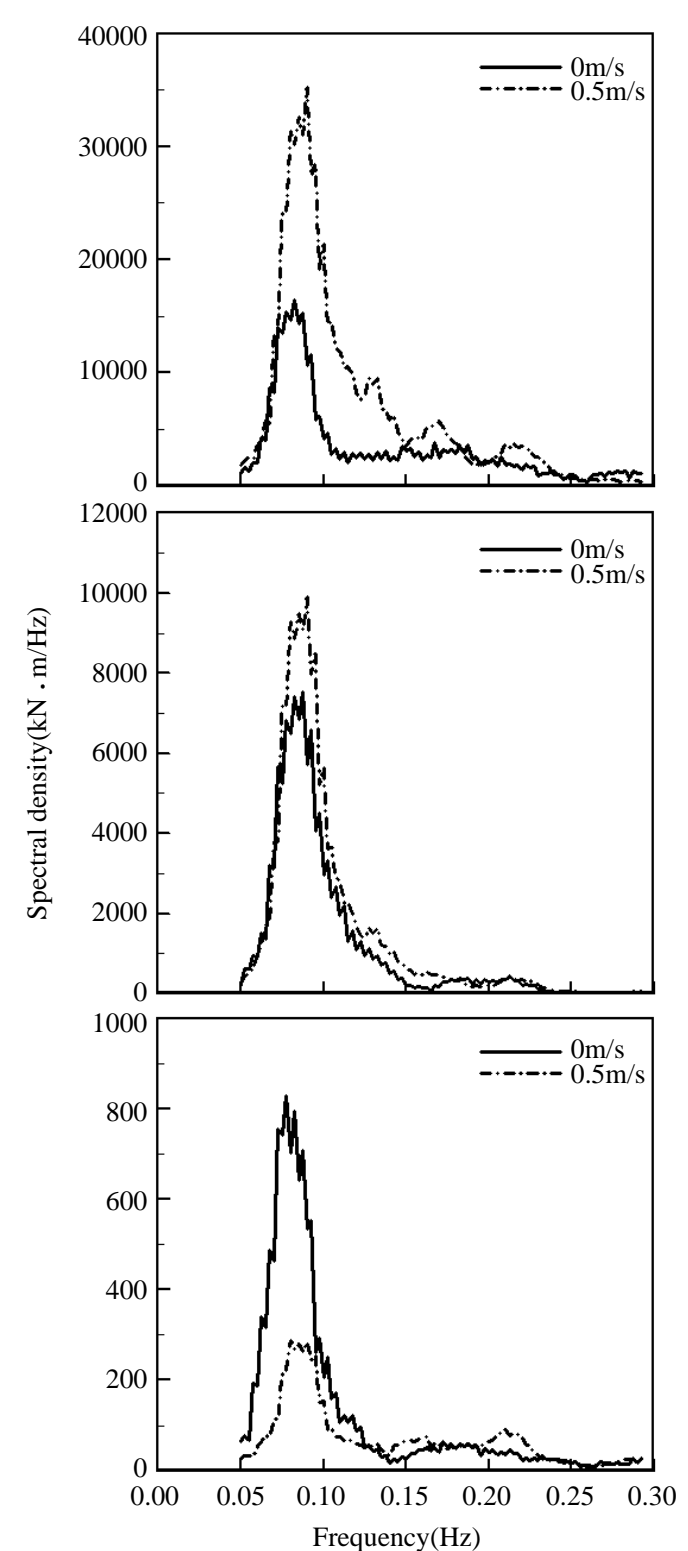

Fig. 6. The mooring tension spectral results at 0 and $0.5 \mathrm{~m} / \mathrm{s}$. The system was at the surface and submerged in a single point mooring. described. Numerical model results for the four fish cage and mooring system configurations were obtained for the surge, heave and pitch motion of the upper ring and the tension in the mooring elements.

Simulations were performed using the JONSWAP wave spectrum with and without the superimposed co-linear current of $0.5 \mathrm{~m} / \mathrm{s}$. The simulations were performed for a duration of 400 sec. Examples of the time series results for the motion and mooring tension of the cage at the surface and submerged for the single point mooring are shown in Fig. 3 and Fig. 4.

Next, using the time series results, the spectral representation of the wave input, motion response in surge, heave and pitch and the mooring tension responses were calculated. The calculations were

Table 4. Significant tension response in the mooring line calculated using the model under irregular waves

\begin{tabular}{lcc}
\hline \multirow{2}{*}{ Configuration } & \multicolumn{2}{c}{ Mooring tension $(\mathrm{kN})$} \\
\cline { 2 - 3 } & $0 \mathrm{~m} / \mathrm{s}$ & $0.5 \mathrm{~m} / \mathrm{s}$ \\
\hline Single point mooring: Surface & & \\
$\quad$ Element \#1 & 116 & 163 \\
Single point mooring: Submerged & & \\
$\quad$ Element \#1 & 68.58 & 77.86 \\
$\quad$ Element \#2 & 22.52 & 16.68 \\
Three point mooring: Surface & & \\
Element \#1 & 116 & 128 \\
Element \#2 & 46 & 133 \\
Element \#3 & 8.17 & 7.39 \\
Element \#4 & 8.28 & 7.40 \\
Three point mooring: Submerged & & \\
Element \#1 & 72.6 & 83.5 \\
Element \#2 & 22.6 & 22 \\
Element \#3 & 2.26 & 38.97 \\
Element \#4 & 1.83 & 0.76 \\
Element \#5 & 1.87 & 0.75 \\
\hline
\end{tabular}

Table 3. Significant motion response of submersible fish cage calculated using the model under irregular waves

\begin{tabular}{|c|c|c|c|c|c|c|}
\hline \multirow{2}{*}{ Configuration } & \multicolumn{2}{|c|}{ Surge(m) } & \multicolumn{2}{|c|}{ Heave(m) } & \multicolumn{2}{|c|}{ Pitch(rad) } \\
\hline & $0 \mathrm{~m} / \mathrm{s}$ & $0.5 \mathrm{~m} / \mathrm{s}$ & $0 \mathrm{~m} / \mathrm{s}$ & $0.5 \mathrm{~m} / \mathrm{s}$ & $0 \mathrm{~m} / \mathrm{s}$ & $0.5 \mathrm{~m} / \mathrm{s}$ \\
\hline Single point mooring: Surface & 4.02 & 4.16 & 2.56 & 1.93 & 0.10 & 0.10 \\
\hline Single point mooring: Submerged & 3.34 & 3.27 & 0.33 & 1.07 & 0.04 & 0.05 \\
\hline Three point mooring: Surface & 3.27 & 1.87 & 2.90 & 2.99 & 0.12 & 0.17 \\
\hline Three point mooring: Submerged & 3.31 & 1.91 & 0.26 & 0.77 & 0.03 & 0.09 \\
\hline
\end{tabular}



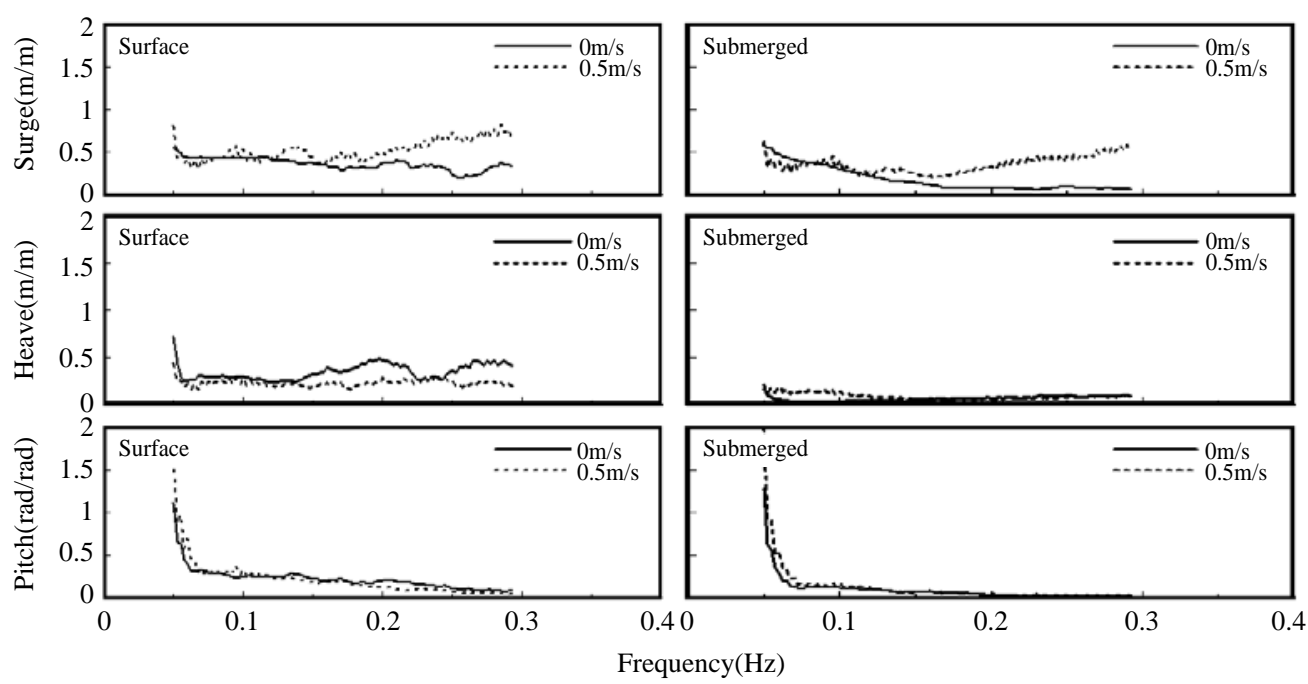

Fig. 7. The motion transfer function results at 0 and $0.5 \mathrm{~m} / \mathrm{s}$ for the surface and submerged in a single point mooring.

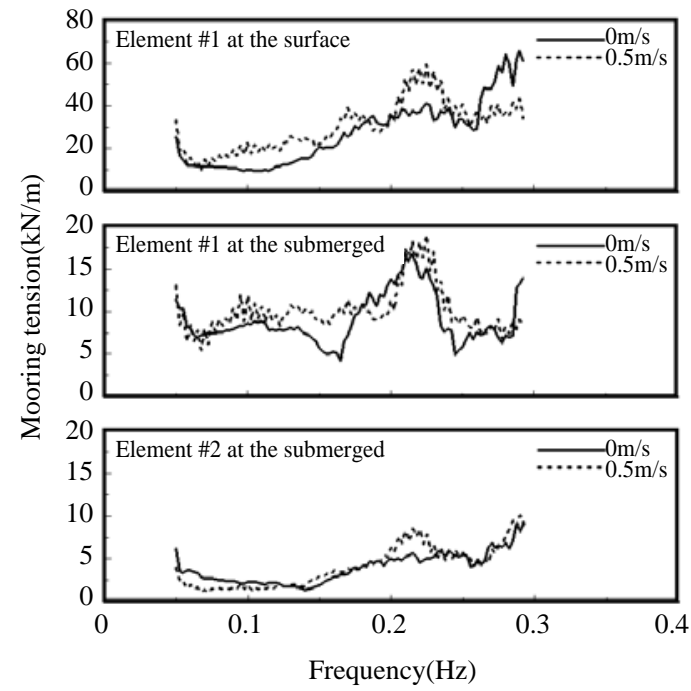

Fig. 8. The mooring tension transfer function results at 0 and $0.5 \mathrm{~m} / \mathrm{s}$ for the surface and submerged in a single point mooring.

performed using equations (4) and (5) to obtain the wave elevation $\left(G_{\eta \eta}\right)$, surge $\left(G_{s s}\right)$, heave $\left(G_{h h}\right)$, pitch $\left(G_{p p}\right)$ and mooring element tension $\left(G_{t t}\right)$ response spectra. The input wave spectrum was used with equations (6) and (7) to calculate the wave excursion $\left(G_{\tau \tau}\right)$ and wave slope $\left(G_{\theta \theta}\right)$ spectra.
Examples of the wave spectrum parameter input and the motion and mooring tension spectral results of the cage at the surface and submerged for the single point mooring are provided in Fig. 5 and Fig. 6.

The wave parameter input, the fish cage motion response and the mooring tension response spectra were used with equations (8), (9), (10) and (11) to obtain the surge, heave, pitch and mooring tension linear transfer functions. Examples of the motion and mooring tension transfer function plots of the cage at the surface and submerged for the single point mooring are provided in Fig. 7 and Fig. 8.

In addition to the transfer function calculations, the motion and tension response was characterized by the zeroth moment of each spectral response using equation (2) and (3). The results for equation (2) called the significant response, are provided in Tables 3 and 4 for the fish cage surge, heave, pitch and the mooring element tensions. The Table 3 and 4 show the motion and tension response differences between the wave input with and without a $0.5 \mathrm{~m} / \mathrm{s}$ co-linear current. The surge motion was prominent for surface and submerged condition in the single 
and three point mooring configuration. The heave motion of the fish cage submerged below $15 \mathrm{~m}$ of the mean water line was smaller $87 \%$ and $91 \%$ than those at the surface for the single and three point moorings, respectively. Currents hardly influenced the oscillatory motion of the cage except surge motion for the three point mooring.

Mooring line tensions in both wave and current exceeded by 1.4 to 1.6 times to those calculated using wave only. Mooring line tensions of the fish cage submerged was smaller by $42 \%$ and $47 \%$ than those at the surface for the single and three point mooring configuration, respectively.

It is important to note that the results of the model tests are approximate. The model does have limitations especially with regard to element shading. For example, the model applies the input conditions(for each time step) to every element regardless of the location. A cage in the ocean, however, can be subject to component shadowing, where one component(the net for example) is in the wake of another. This effect has been observed in a similar cage deployed in the Gulf of Maine (Fredriksson et al., 2003d) where current velocities were reduced by as much as $10 \%$ as it passed through the net. This phenomenon has also been investigated through a series of tank tests and analytical approaches by L $\phi$ land(1991).

\section{Conclusion}

A numerical model analysis was performed to analyze the motion and mooring tension response of submersible fish cage systems. Using a Morison equation type model, simulations of the systems were conducted with the cage at the surface and submerged. Irregular waves(JONSWAP spectrum) with and without a co-linear current with a magnitude of $0.5 \mathrm{~m} / \mathrm{s}$ were forced into the model as input parameters. Surge, heave and pitch dynamic calculations were made, along with tension responses in the mooring lines. Results were analyzed in both the time and frequency domains and linear transfer functions were calculated. The surge motion was prominent for surface and submerged condition in the single and three point mooring configuration. Further verifications by physical model tests and field measurements are needed in order to more accurately analyze hydrodynamic characteristics of the cage system.

\section{Acknowledgements}

This work was supported by the Korea Research Foundation Grant funded by the Korean Government(MOEHRD) (KRF-2005-003-F00020).

\section{References}

DeCew, J., D.W. Fredriksson, L. Bougrov, M.R. Swift, O. Eroshkin and B. Celikkol, 2005. Numerical and physical modeling of a modified gravity type cage and mooring system. IEEE J. Oceanic Eng., 30(1), $47-58$.

Fredriksson, D.W., M.R. Swift, J.D. Irish, I. Tsukrov and B. Celikkol, 2003a. Fish cage and mooring system dynamics using physical and numerical models with field measurements. Aqua. Eng., 27(2), 117 - 270.

Fredriksson, D.W., M.R. Swift, J.D. Irish and B. Celikkol, 2003b. The heave response of a central spar fish cage. Transactions of the ASME, J. of Off. Mech. and Arct. Eng., 25, 242 - 248.

Fredriksson, D.W., M.J. Palczynski, M.R. Swift and J.D. Irish, 2003c. Fluid dynamic drag of a central spar cage open ocean aquaculture IV. June 17-20, St. Andrews, NB, Canada, Mississippi-Alabama Sea Grant Consortium, Ocean Springs, MS. MASGP-01006, 2001. 151 - 168.

Fredriksson, D.W., I. Tsukrov, K. Baldwin, M.R. Swift and B. Celikkol, 2003d. Open ocean fish cage and mooring system modeling. Fisheries Dynamics 
2003. National Fisheries Research and Development Institute. Busan. Korea, 109 - 122.

Fredriksson, D.W., M.R. Swift, O. Eroshkin, I. Tsukrov, J.D. Irish, and B. Celikkol, 2005. Moored fish cage dynamics in waves and currents. Special Issue on Open Ocean Aquaculture Engineering. IEEE J. Oceanic Eng., 30(1), 28 - 36.

Goda, Y., 2000. Random seas and the design of maritime structures. World Scientific Publishing Company, New Jersey, pp. 443.

Haritos, $\mathrm{N}$ and D. T. He., 1992. Modelling the response of cable elements in an ocean environment. Fin. Elem. in Analysis and Des., 19, 19 - 32.

Hasselmann, K., 1973. Measurements of wind-wave growth and swell decay during the Joint North Sea Wave Project(JONSWAP). Deutsche Hydrographische Zeitschrift, Reihe. 12. pp. 95.

Kim, T.H., 2006. Mooring loads analysis of submersible aquaculture cage system using finite element method. J. Kor. Fish. Tech., 42(1), 44 - 53.
Morison, J.R., J.W. Johnson, M.P. O' Brien and S.A. Schaaf, 1950. The forces exerted by surface waves on piles. Petroleum Transactions, American Inst. of Mining Eng., 149 - 157.

Ochi, M.K., 1998. Ocean waves: The Stochastic approach. Cambridge University Press, New York. pp. 331.

Shore Protection Manual, 1984. US Army engineer waterways experiment station. 4th ed., 2 Vols. Coastal Engineering Research Center, US Government Printing Office, Washington, DC. pp. 432.

Tsukrov, I., O. Eroshkin, D.W. Fredriksson, M.R. Swift, and B. Celikkol, 2003. Finite element modeling of net panels using consistent net elements. Ocean Eng., 30, 251 - 270.

Tsukrov, I, O. Eroshkin, W. Paul and B. Celikkol, 2005. Numerical modeling of nonlinear elastic components of mooring systems. IEEE J. Oceanic Eng., 30(1), $37-46$.

2007 년 10 월 9 일 접 수

2008 년 1월 2 일 수리 